Revista de Investigación Educativa 27

julio-diciembre, 2018 | ISSN 1870-5308 | Xalapa, Veracruz

Instituto de Investigaciones en Educación | Universidad Veracruzana

\title{
Cambio de estafeta y nuevos retos...
}

Laura Selene Mateos Cortés ${ }^{\mathrm{a}}$

a publicación insignia del Instituto de Investigaciones en Educación (IIE) de
la Universidad Veracruzana, CPU-e Revista de Investigación Educativa, creada en 2005 , se encuentra ante un reto que enfrentan muchas iniciativas académicas en nuestro campo - el de pasar de una fase de consolidación institucional a otra de internacionalización-. El Director saliente de la revista CPU-e, Miguel Figueroa Saavedra-Ruiz, ha logrado durante su gestión encauzar decisivamente las actividades de producción, difusión y coordinación de la revista logrando consolidarla. Mi labor principal como Directora entrante consistirá, por tanto, en apoyar y coordinar procesos en curso, mantener los niveles de calidad obtenidos y consolidar los mecanismos y marcos institucionales que permiten la producción de la revista en los ritmos y plazos establecidos y su visibilización a nivel local, nacional e internacional.

De la misma forma que — gracias al formato digital — estamos logrando llegar a lectores procedentes no sólo de la Universidad Veracruzana, sino igualmente del ámbito académico y educativo mexicano, latinoamericano e hispanohablante, en general, ahora nos abocamos a la tarea de diversificar de manera semejante nuestro abani-

a Doctora. Directora de la CPU-e, Revista de Investigación Educativa. Investigadora, Instituto de Investigaciones en Educación, Universidad Veracruzana, México.凶l lauramat@gmail.com 
co de autores. Para incrementar la visibilidad de la revista, pretendemos "captar" cada vez más autores internacionales y nacionales en temáticas que favorezcan la difusión de la revista CPU-e y su respectiva citación.

De forma paralela y simultánea, estamos actualmente revisando y actualizando la cartera de árbitros de las diferentes áreas temáticas que conforman la revista. Mediante la lista de correos electrónicos, pero pronto también mediante nuestra presencia en redes sociales como Facebook y Twitter, se difundirán los números publicados para divulgar la revista y al mismo tiempo invitar a futuros autores. Para lograr lo anterior, hemos recurrido a contactos internacionales y nacionales de los integrantes del comité editorial de la revista, del comité editorial del IIE y de los investigadores de las líneas que conforman el iIE de la Universidad Veracruzana.

Hago, por tanto, un llamado a investigadores en educación, tanto a noveles investigadores en formación como a colegas consolidados, a participar en las actividades de nuestra revista, sea contribuyendo como autores de artículos de investigación, sea proponiendo reseñas o libros a reseñar, sea formando parte de nuestra cartera de árbitros.

Adicionalmente, para poder difundir mejor a nivel internacional los artículos publicados en nuestra revista, estamos actualizando la página web de la CPU-e y, a la vez, asegurando su presencia en bases de datos tales como REDALYC, Latindex, IRESIE, DOAJ y SCIELO. Nuestro equipo editorial se ha capacitado y actualizado en los respectivos paquetes de software, y nuestra revista ya forma parte del portal editorial de revistas oficiales de la Universidad Veracruzana. Actualmente trabajamos, de forma conjunta con la Editorial de la Universidad Veracruzana, en la habilitación total del Open Journal Systems para gestionar de forma más eficaz el trabajo de dictaminación, producción y publicación de la revista. En este sentido, nos encontramos regularizando, optimizando y acelerando, en la medida de lo posible, los procesos editoriales de la $C P U-e$, reduciendo al mínimo posible el tiempo que transcurre entre la aprobación (o el rechazo) de manuscritos para su dictaminación y su posterior publicación, algo que consideramos un servicio importante para nuestros autores prospectivos, aparte de constituir uno de los requisitos indispensables para permanecer en los catálogos de indización. Para realizar dicha labor, uno de los retos ha sido integrar procesos de gestión y distribución de tareas y actividades entre el comité editorial, los editores y los colaboradores externos.

Para revisar y vigilar continuamente el prestigio de la revista, así como para mantener y asegurar los estándares de calidad académica que ha ido adquiriendo en los 
últimos años, hemos ampliado el comité editorial invitando a investigadores de reconocido prestigio tanto a nivel nacional como internacional. Estos colegas, junto con los miembros del comité editorial de la CPU-e, con los miembros del comité editorial del IIE y con el conjunto de investigadores del IIE, nos apoyan para promocionar la revista, particularmente entre jóvenes investigadores que se encuentran realizando algún posgrado en investigación educativa y que deseen publicar resultados parciales o finales de sus respectivos proyectos de investigación.

Por último, con el objetivo de internacionalizar y de "multilingüizar" decididamente nuestra revista, estamos iniciando un proceso de traducción, por el momento, al inglés de la página de la CPU-e, así como de algunos elementos de cada publicación (títulos, resúmenes y palabras claves de los artículos). Además de integrar a miembros extranjeros en el comité editorial y en nuestra cartera de árbitros, gracias a lo cual podremos ir aceptando publicaciones en otros idiomas, tanto en lenguas extranjeras como en lenguas originarias.

Reitero por tanto nuestra invitación a sumarse a esta iniciativa de publicar en CPU-e, Revista de Investigación Educativa, trabajos de investigación educativa concluidos o por concluir, provenientes del ámbito local, nacional o internacional, redactados en una de las principales lenguas de comunicación científica o en alguna de las lenguas originarias. Ofrecemos a cambio un medio de publicación académica de reconocido prestigio, completamente gratuito, de acceso libre, indizado y con ello certificado por seguir criterios y perfiles de calidad en la investigación. 